\title{
Principles in Practice and the 'Footprint' of the US Student Abroad
}

Brigham Young University's International Field Study Program has several guiding principals. Among these are that students are prepared before entering the field to do serious research in a topic that relates to their major, that they will be in the host country for at least three months and will become fully immersed in the local culture, that they will receive mentoring for their research but will be able to conduct independent research, and that they reciprocate to their hosts by providing service in the local community. Colin Smith's experience in South Africa and his research on the role of storytelling in the Xhosa culture met all of these guiding principals.

Colin spent more than three months in East London, South Africa during the Spring and Summer of 2004. East London is in South Africa's Eastern Cape state. As with much of South Africa, African culture (in this case mostly Xhosa) mixes with the British and Afrikaans to give a rich and diverse cultural mosaic. In East London, one can move from wealthy suburbs, through the city center and to the outskirts of town in a fifteen minute drive. In the process one passes in and out of multiple cultures, economic classes, and social groups with astonishing abruptness. For American students, the opportunities for learning are vast. For someone with interest in Apartheid and its aftermath, East London has a wealth of history. Not only did much of the resistance to apartheid come from small towns and townships in this area, but at the demise of apartheid, the first Truth and Reconciliation Commission was held in East London's town hall. And for someone interested in the interaction of cultures, the effect of globalization, and the legacy of colonialism, East London provides a good example of a community struggling with all of these issues.

Because of this cultural richness and because East London has proven to be a safe location in a sometimes violent country, BYU has used East London as the site for its South African field study program for almost ten years. From the beginning, BYU's intent in South Africa was to minimize its "footprint" on the local community. From pedagogical view this was important because BYU did not want create a "cultural bubble" where its students could retreat from the local culture. A small footprint is also important from an economic development viewpoint. Students are encouraged to share their skills with local entities in a way that will benefit the local organization, but are discouraged from starting programs that will not last the student's tenure in the organization or that will 
create dependency on outside funds. From the moment students are accepted into the South Africa program they are trained to view themselves as guests of the local culture who are to interact with and learn from the local culture rather than imposing their own cultural views.

For the most part, minimizing the footprint in East London has been easy. BYU sends few students to East London (usually 7 to 9 per semester) and has no permanent staff there. As can be imagined, though, there are administrative and logistical challenges for even a group of this size. A program like this requires students to be well-trained before arriving in the host country. To meet this requirement, BYU field study students take a full semester course on field research and intercultural communication the semester before they travel abroad. In this course students develop their research question and research plan. They are also asked to grapple with the difficult issues of international development and the ethical questions intercultural experiences can raise. Through writing and class discussion, students spend time thinking in depth about the impact their time in East London will have on their own academic experience, on the host families they will live with, and on the organizations and community they will be working with. Due to the independent nature of these self-directed field studies, students' commitment to responsible and thoughtful interaction becomes crucial. Not surprisingly, Colin proved to be one of the most thoughtful and engaged students in the preparation course before he went.

A second challenge for a program of this nature is the in-field mentoring of the student research. Before leaving the United States, field study students work out "course contracts" with BYU faculty. As a part of this contract students are required to keep in regular contact with these home campus faculty who can then act as mentors through the course of the program. In addition, where possible, a faculty member from BYU also makes a 2-3 week visit sometime over the course of the student's three months experience. This allows the faculty to discuss student's research in situ, connect with the community and perhaps do some research of their own. Students also have a student facilitator (usually an alumnus of the program) on-site who can help with local logistical difficulties. But in the end, a field study experience through BYU requires that a student assume maximum responsibility for both their academic activities and decisions, and their non-academic activities and decisions. This requires from students a high degree of maturity, trustworthiness, self-reliance and experience. But with careful screening and preparation, the program has been able to find students who fit this bill.

Colin's work represents the quality that can come from having field study students in small, independent, and "invisible" groups. For well-prepared 
students like him the opportunity can be life-changing and can lead to development of cultural sensitivities and international awareness that is difficult to achieve in other ways. His work also illustrates the positive impact that these groups can have on those who happen to fall in the program's small "footprint." In addition to the Xhosa host families, this also includes the organizations where the students volunteer their time. Students have worked with government agencies on community planning, with NGOs on literacy programs, and, in Colin's case, with organizations that provide education and help to street children. In all cases students are encouraged to be involved with organizations whose work enhances their research.

This worked well for Colin enabling him to gain deeper insight on the importance of storytelling and on Xhosa culture by working at the Daily Bread youth center. This organization takes in street children and provides them housing and education. In return, for his work at the center, Colin had a chance to observe a slice of Xhosa culture that casual visitors to East London would miss. He also gained a unique perspective on his research topic. And last, certainly not least, the experience strengthened his interest in teaching children (which he has continued to pursue) and his interest in South Africa (which continues as well).

On arriving in South Africa Colin had a research plan and some academic tools to use in doing research. Once in the field it was up to him to adapt this in-class learning to the environment, to become involved in the local community, and, in the process, do serious academic research. His written work illustrates his success at this task.

\section{Timothy Lynn Elliott}

Director, International Study Programs

Brigham Young University

\section{J ulie Johnson}

South Africa in-country facilitator for Brigham Young University Programs 